\title{
Maternally Contributed Folate Receptor 1 Is Expressed in Ovarian Follicles and Contributes to Preimplantation Development
}

\author{
Trine Strandgaard ${ }^{1 \dagger}$, Solveig Foder ${ }^{1 \dagger}$, Anders Heuck ${ }^{1}$, Erik Ernst ${ }^{2}$, Morten S. Nielsen ${ }^{1,3}$ \\ and Karin Lykke-Hartmann ${ }^{1,4,5 *}$
}

${ }^{1}$ Department of Biomedicine, Aarhus University, Aarhus, Denmark, ${ }^{2}$ Department of Gynaecology and Obstetrics, Aarhus University Hospital, Aarhus, Denmark, ${ }^{3}$ Lundbeck Foundation Research Initiative on Brain Barriers and Drug Delivery, Aarhus University, Aarhus, Denmark, ${ }^{4}$ Department of Clinical Medicine, Aarhus University, Aarhus, Denmark, ${ }^{5}$ Department of Clinical Genetics, Aarhus University Hospital, Aarhus, Denmark

\section{OPEN ACCESS}

Edited by:

Tomer Avidor-Reiss, University of Toledo, United States

Reviewed by:

Richard Eugene Frye, University of Arkansas for Medical

Sciences, United States Daniel Rossignol, Rossignol Medical Center United States

Alfredo Ulloa-Aguirre, National Autonomous University of

Mexico, Mexico

${ }^{*}$ Correspondence:

Karin Lykke-Hartmann

kly@biomed.au.dk

${ }^{\dagger}$ These authors have contributed equally to this work

Specialty section

This article was submitted to Cell Growth and Division,

a section of the journal

Frontiers in Cell and Developmental

Biology

Received: 02 August 2017 Accepted: 19 September 2017 Published: 28 September 2017

Citation:

Strandgaard T, Foder S, Heuck A, Ernst $E$, Nielsen MS and Lykke-Hartmann K (2017) Maternally Contributed Folate Receptor 1 is Expressed in Ovarian Follicles and

Contributes to Preimplantation

Development

Front. Cell Dev. Biol. 5:89.

doi: 10.3389/fcell.2017.00089
Folates have been shown to play a crucial role for proper development of the embryo as folate deficiency has been associated with reduced developmental capacity such as increased risk of fetal neural tube defects and spontanous abortion. Transcripts encoding the reduced folate carrier RFC1 (SLC19A1 protein) and the high-affinity folate receptor FOLR1 are expressed in oocytes and preimplantation embryos, respectively. In this study, we observed maternally contributed FOLR1 protein during mouse and human ovarian follicle development, and 2-cell mouse embryos. In mice, FOLR1 was highly enriched in oocytes from primary, secondary and tertiary follicles, and in the surrounding granulosa cells. Interestingly, during human follicle development, we noted a high and specific presence of FOLR1 in oocytes from primary and intermediate follicles, but not in the granulosa cells. The distribution of FOLR1 in follicles was noted as membrane-enriched but also seen in the cytoplasm in oocytes and granulosa cells. In 2-cell embryos, FOLR1-eGFP fusion protein was detected as cytoplasmic and membrane-associated dense structures, resembling the distribution pattern observed in ovarian follicle development. Knock-down of Folr1 mRNA function was accomplished by microinjection of short interference (si)RNA targeting Folr1, into mouse pronuclear zygotes. This revealed a reduced capacity of Folr1 siRNA-treated embryos to develop to blastocyst compared to the siRNA-scrambled control group, indicating that maternally contributed protein and zygotic transcripts sustain embryonic development combined. In summary, maternally contributed FOLR1 protein appears to maintain ovarian functions, and contribute to preimplantation development combined with embryonically synthesized FOLR1.

\section{Keywords: folate receptor 1, follicle development, preimplantation development, siRNA, blastocyst}

\section{INTRODUCTION}

It is well-established that folates are important for the development of the embryo. Pregnant women are advised to take a dietary supplement of $400 \mathrm{mg}$ folic acid per day from 12 weeks before conception and during the first trimester of pregnancy (Hibbard, 1964; Cawley et al., 2016). Folate deficiency has been associated with increasing the risk of neural tube defects (NTD) 
(Detrait et al., 2005; Pitkin, 2007), early spontaneous abortion (George et al., 2002), congenital heart defects (Rosenquist et al., 2010) and orofacial clefts (Taparia et al., 2007) amongst others.

The folate receptor is highly expressed in reproductive tissues thereby providing folate to the embryo (da Costa et al., 2003). Deficiency in folate uptake can cause pregnancyrelated complication such as NTD, a well-established association (Centers for Disease Control, 1991a,b; MRC Vitamin Study Research Group, 1991; Czeizel and Dudas, 1992; Cragan et al., 1995). Interestingly, the identification of folate receptor autoantibodies in in women with recurrent NTD pregnancies might mechanistically explain how the embryo is deprived of folate (Rothenberg et al., 2004; Berrocal-Zaragoza et al., 2009; Sequeira et al., 2013). Additionally, variation in folate pathway genes are associated with female infertility (Altmae et al., 2010). In line with this, postnatally acquired FR autoantibodies blocking folate transport to the brain have been associated with the infantile-onset cerebral folate deficiency syndrome (Ramaekers et al., 2005), which in a number of patients manifests as low-functioning autism with neurological deficits (Ramaekers et al., 2007). Folic acid supplementation in pregnancy may have beneficial effects on the neurodevelopment of children, such as cerebral folate deficiency syndrome and autism spectrum disorders (Desai et al., 2016), beyond its proven effect on NTDs (Blencowe et al., 2010; De-Regil et al., 2015; Gao et al., 2016).

It is proposed that folate deficiency affects gene expression by disrupting DNA methylation patterns or by inducing base substitutions, DNA breaks, gene deletions and gene amplification (Crott et al., 2008). In line with this, mutations in the enzyme methionine synthase reductase (Mtrr), necessary for utilization of methyl groups from the folate cycle, affect the folate metabolism and cause epigenetic instability (Padmanabhan et al., 2013). The phenotypes of the Mtrr-deficient mice included congenital malformations with neural tube, heart and placental defects, which persisted for five generations, through transgenerational epigenetic inheritance (Padmanabhan et al., 2013). Folates are co-enzymes responsible for the 1-carbon (1C) unit transfer important for purine, pyrimidine and methionin synthesis, and glycine and serine metabolism (Fowler, 2001). The methionine synthesized from homocysteine in the folate cycle is the only significant source (in most cells) of the universal methyl donor, $S$-adenosyl methionine (SAM), and is essential for methylation processes (Stover, 2009). Although folates are recycled in the folate cycle, it is essential to accumulate as folates are degraded. Folates, where 5-methyl-THF is the predominant bioavailable form in mammals, can either be taken up directly from dietary sources or produced by metabolism of dietary folic acid (Kooistra et al., 2013).

Folate is principally taken up into cells by a reduced folate carrier, RFC1, and by two different folate receptors with high affinity for folate, FOLR1 and FOLR2 (Kooistra et al., 2013). Other members of the receptor family are FOLR3 and FOLR4. The folate receptors are attached to the extracellular side of the membrane by a glycosylphosphatidylinositol anchor (GPIanchor). The folate receptors are heavily glycosylated and bind folic acid and 5-methyl-tetrahydrofolate (5-methyl-THF) with high affinity (Brigle et al., 1994; Chen et al., 2013). RFC1 has been reported expressed in cumulus-oocyte-complexes (COC) but not in preimplantation embryos, suggesting a role in folate accumulation in the COC cells, but without transport into the enclosed oocyte (Kooistra et al., 2013). FOLR1 has been shown to be an important receptor for the uptake of folates into the cells and has been found expressed in mouse preimplantation embryos, increasing from the 2-cell stage onwards (Kooistra et al., 2013). FOLR2 has not been reported expressed in neither COC nor preimplantation embryos (Kooistra et al., 2013) and binds folic acid with lower affinity than FOLR1 (Brigle et al., 1994). FOLR3 does bind folic acid, but it is a constitutively secreted protein rather than a membrane bound one, probably due to the lack of an efficient signal for glycosylphosphatidylinisotol (GPI)-anchor attachment (Shen et al., 1995). FOLR4 (Juno (FR-d in humans)) is not a typical member of the Folate Receptor Family, but share a high structural homology with FOLR1 (Spiegelstein et al., 2000). Juno-deficient mice are infertile (Bianchi et al., 2014).

The basis of folate supplementation of folate has been administrated as oral or intravenous folinic acid (5formyltetrahydrofolate) treatments that has been shown to improve clinical status. Folinic acid can be transported through the RFC and participate in folate dependent reactions compared to both folic acid and MTHF that needs further processing (Desai et al., 2016; Frye et al., 2016; Ramaekers et al., 2016).

Mice deficient of Folr1 are defective in early embryonic development (Piedrahita et al., 1999), in contrast to Folr2deficient mice that developed normally (Piedrahita et al., 1999). Folr $1^{-/}$embryos died at day E10 with severe morphological abnormalities, and interestingly, these phenotypes could be reverted by maternal supplement of Folr ${ }^{+/-}$dams with folic acid (Piedrahita et al., 1999). The curly tail (ct) mouse provides a model for neuronal tube defects (spina bifida and exencephaly) (Van Straaten and Copp, 2001). However, folate supplement does not prevent NTD in $c t / c t$ embryos (Burren et al., 2010), but formate supplementation enhanced the folate-dependent nucleotide biosynthesis and prevented spina bifida (Sudiwala et al., 2016). Interestingly, primary cultures of mouse embryonic fibroblasts established from Folr $1^{-/-}$embryos revealed altered signal transduction in pathways including transforming growth factor beta 1 (TGF $\beta 1$ ) and the canonical Wnt signaling pathways suggesting that pathways for proper development are significantly altered (Warner et al., 2011).

Besides a role in signal transduction, it has been shown that FOLR1 can act as a transcription factor. In cell lines, FOLR1 translocated to the nucleus and interacted with FGFR4 and HES1, and was suggested to regulate a wide range of developmental genes (Boshnjaku et al., 2012).

In this study, we noted the presence of maternally contributed FOLR1 during mouse and human ovarian follicle development. In mouse follicles, the presence of FOLR1 was observed in both oocytes and the surrounding granulosa cells. In contrast, FOLR1 was restricted to oocytes in follicles from human tissue. In 2-cell embryos, FOLR1-eGFP fusion protein was detected as cytoplasmic and membrane-associated dense structures, resembling the observed cellular localization in ovarian follicle development. 
Microinjections of short interference (si)RNA probes targeting the Folr1 transcript revealed an efficient knock-down of the embryonic Folr 1 transcript. Interestingly, siRNA-mediated knock-down of Folr 1 in zygotes reduced the ability of embryos to develop to blastocyst. This indicates that maternally contributed FORLR1 protein and zygotically synthesized Folr1 transcripts sustain embryonic development combined.

\section{RESULTS}

\section{Folr1 Transcript is Detectable from 2-Cell Stage Onwards during Mouse Preimplanation Development}

We first wished to analyse if the Folr1 transcript would be expressed in germinal vesicle (GV) and metaphase II (MII) oocytes as well as during preimplantation development, and thus, if the transcript would be expressed solely from the zygotic genome. Toward this end, RT-qPCR was performed to analyse the expression pattern of Folr1 during preimplantation stages of embryonic development (Figure 1). Histone H2a.z mRNA was used as the most stable internal reference gene during preimplanation development (Jeong et al., 2005; Albertsen et al., 2010). The expected size of Folr1 and H2af.z PCR products were verified by gel electrohoresis (data not shown). The qPCR analysis revealed that Folr 1 was detectable at very low expression at the 2-cell stage, and then its transcript gradually increased to the blastocyst stages (Figure 1). We observed no detecable levels of Folr1 in GV and MII oocytes (Figure 1). We used tissue from kidney to successfully verify the primer efficiency Figure 1.

This suggests that the Folr1 transcription is initiated during the first wave of genomic transcripton activation during the 2-cell stage, and remains expressed during preimplantation development.

\section{FOLR1 in Mouse Ovarian Tissue}

As we did not detect any Folr1 transcript before the 2cell stage, we asked if there might be a maternal supply of FOLR1 protein during folliculogenesis. We set out to interrogate the presence and distribution of maternal FOLR1 in mouse ovarian tissue by immunohistochemistry (IHC). Firstly, Western blot analysis was performed to confirm the specificity of the FOLR1 antibody. Western blotting revealed a single protein band of approximately $50 \mathrm{kDa}$ in both ovarian tissue and the kidney control sample (Figure 2A). FOLR1 was estimated to provide a band of approximately $30 \mathrm{kDa}$, indicating that post-translational modifications such as glycosylation might be added to the receptor. To verify this, the samples were treated with the Endoglycosidase $\mathrm{H}$, a recombinant glycosidase that cleaves within the chitobiose core of high mannose and some hybrid oligosaccharides from $N$-linked glycoproteins. After endoglycosidase $\mathrm{H}$ treatment, FOLR1 was deglycosylated and a protein band of $30 \mathrm{kDa}$ was observed in ovarie and kidney lysates (Figure 2A). The ability of the FOLR1 antibody to specifically detect FOLR1 in paraffin-embedded was verified on a positive kidney control (Figure 2B). A negative control (no primary
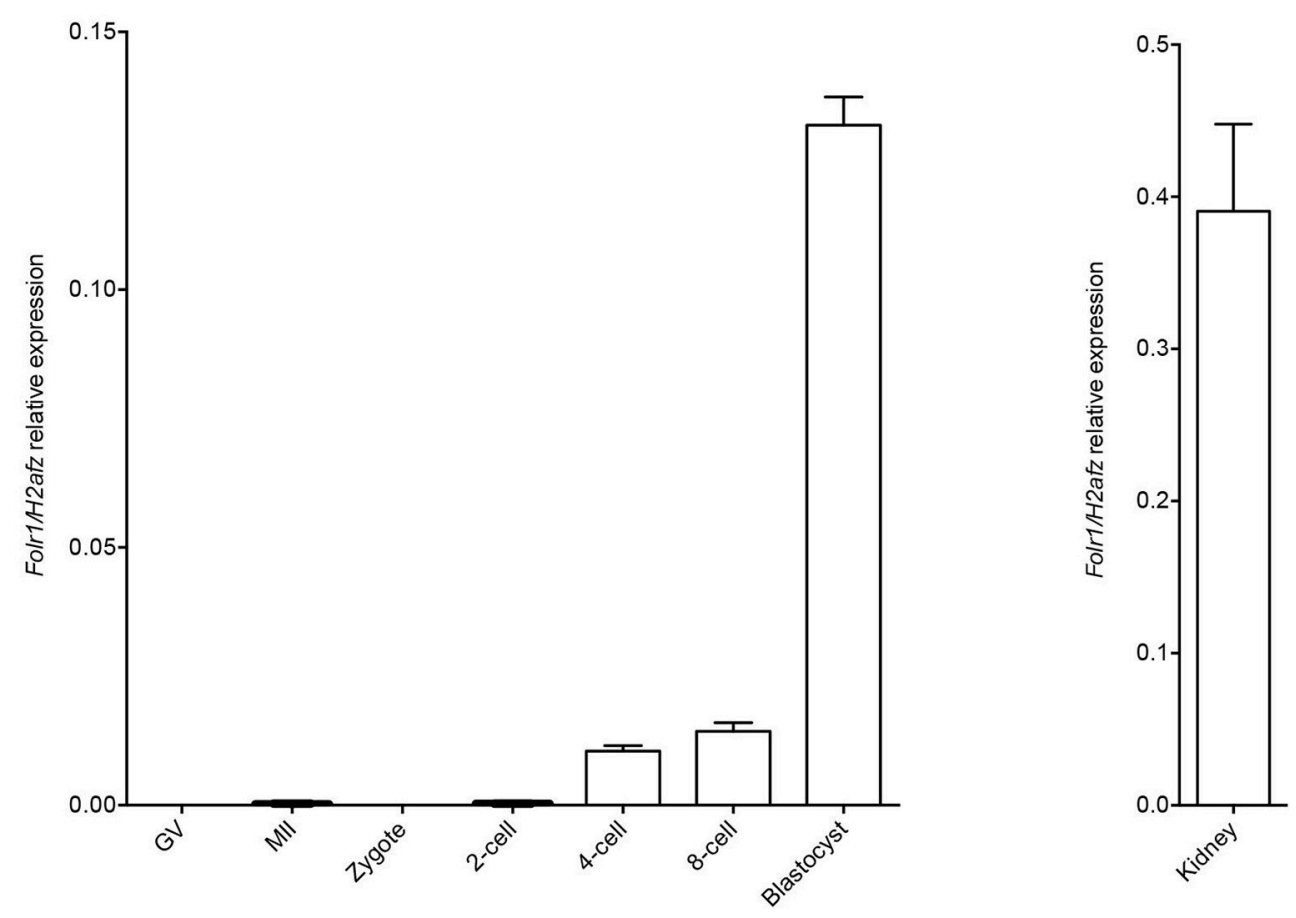

FIGURE 1 | Folr1 gene expression in oocytes and preimplantation embryos. Folr1 expression and relative abundan in GV and MII oocytes and preimplantation embryos, as indicated. Kidney tissue was included as a positive control. Folr1 expression levels were normalized by H2afz and relative expression displayed. Data are presented as mean standard deviation SD (bars) of triplicate measurements including standard deviations. 


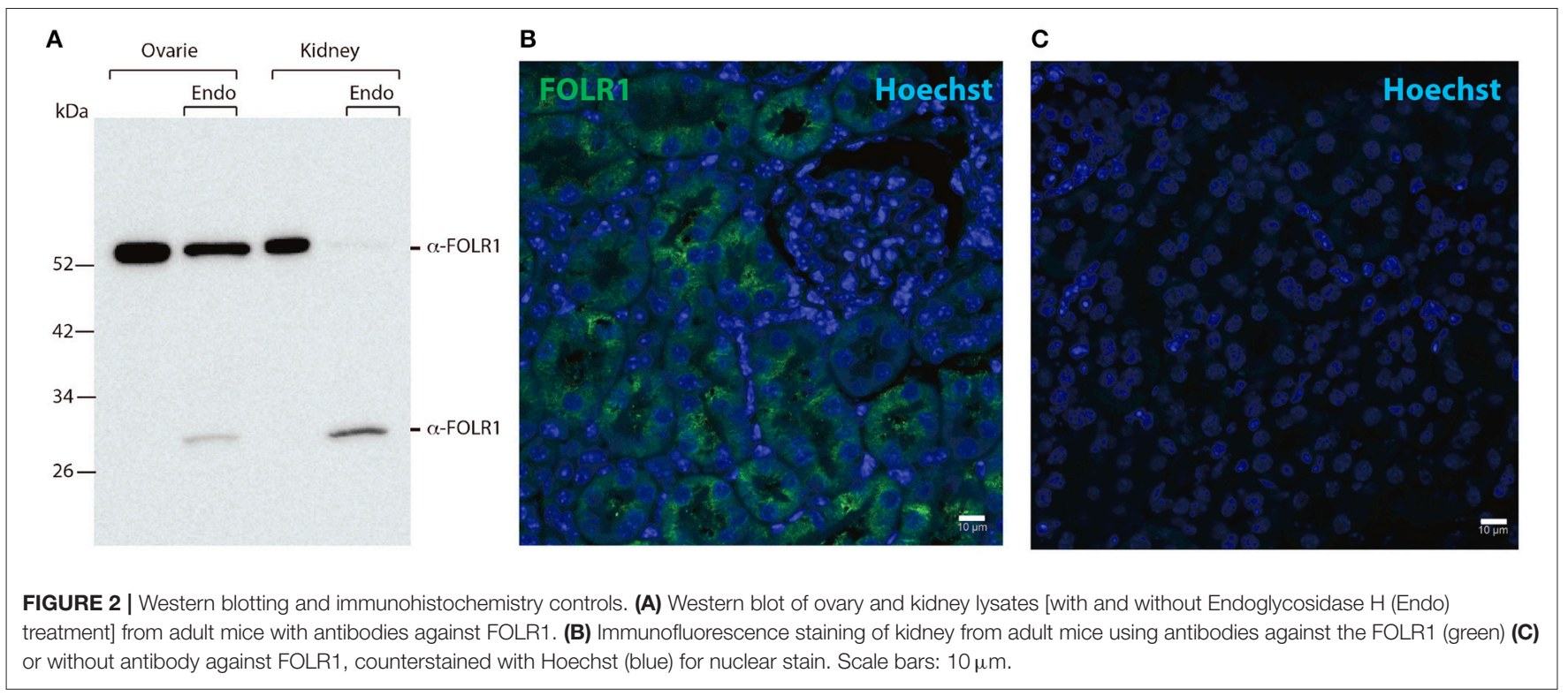

antibody) was included and revealed no detectable staining (Figure 2C).

To determine the presence and intraovarian distribution of FOLR1 in the ovary, IHC was performed on paraffinembedded and sectioned tissue. In the mouse ovary, the FOLR1 was observed in both oocytes and the surrounding granulosa cells in the tested stages of follicles (Figure 3), indicating that FOLR1 transport is possible in both germ and somatic cells. In human, the FOLR1 was strongly noted in the oocytes of the included follicle stages (Figure 4), and in contrast to the FOLR1 distribution in mice, no FOLR1 was detected in the granulosa cells.

In summary, a pronounced FOLR1 localization was observed in the periphery of the cells compared to the cytoplasm.

\section{FOLR1 Distribution in Mouse 2-Cell Embryos}

In order to test if the FOLR1 would display a dynamic intracellular distribution upon fertilization, FOLR1 was fused to enhanced green fluorescent protein (eGFP), to enable us to follow its dynamics and distribution. However, no dynamics was observed in the distribution of FOLR1 between zygotes and 2-cell stage embryos (data not shown). The FOLR1-EGFP distributed in vesicle-like structures in the periphery of the cell membrane, as well as in the cytoplasm (Figure 5). As a control, eGFP localization was observed in the 2-cell embryo, which revealed no specific distribution (Figures 6A,B). In the 2-cell stage (as in zygotes), the FOLR1-eGFP fusion protein resembled that observed for FOLR1 IHC in oocytes and granulosa cells in the ovaries.

\section{siRNA-Mediated Knockdown of Folr1 Compromised Early Developmental Potential}

In order to reveal whether or not newly generated zygotic Folr1 transcripts would be necessary to support early development (along side the maternally contributed FOLR1 protein), RNA interference (RNAi) was used as an approach to knockdown Folr1 transcript. SiRNA-mediated knock-down of the Folr1 transcript was accomplished by microinjection into mouse pronuclear zygotes. SiRNA probes targeting Folr1 or scrambled (non-targeting) RNA (co-microinjected with rhodamine-conjugated dextran into zygotes in order to identify embryos that has received siRNAs) were microinjected into zygotes at the pronuclear stage (three independent experiments) (Figure 7A). After an overnight in vitro incubation, 2-cell stage embryos were collected for $\mathrm{qPCR}$ analysis, which revealed that the Folr1 transcript was effectively reduced in Folr1 siRNAmicroinjected embryos (Figure 7A).

The embryos were subsequently monitored for their ability to develop into blastocysts. In the group of embryos injected with siRNA scrambled, $92 \%$ (21 out of 23) of the 2-cell stage embryos developed into blastocyst, where in the group that received siRNA targeting Folr1, only 56\% (14 out of 25) of the 2-cell stage embryos developed into blastocysts Figure 7B.

This indicates that zygotic Folr1 is indeed required to foster development, however, maternally contributed FOLR1 protein can sustain embryonic development. It might be that this is a finetuned gradient and dependent on the level of maternal FOLR1 protein contributed.

\section{DISCUSSION}

Dysfunctional maternal folate metabolism caused by folate deficiency or polymorphisms are associated with congenital abnormalities, intrauterine growth restrictions, placental and cardiovascular abnormalities as well as neural tube defects in human. While parts of the abnormalities can be directly associated with the embryonic expression of FOLR1, it is likely that maternally contributed FOLR1 might already mark ovarian cells before fertilization, and influence pre- and postimplantation development. 

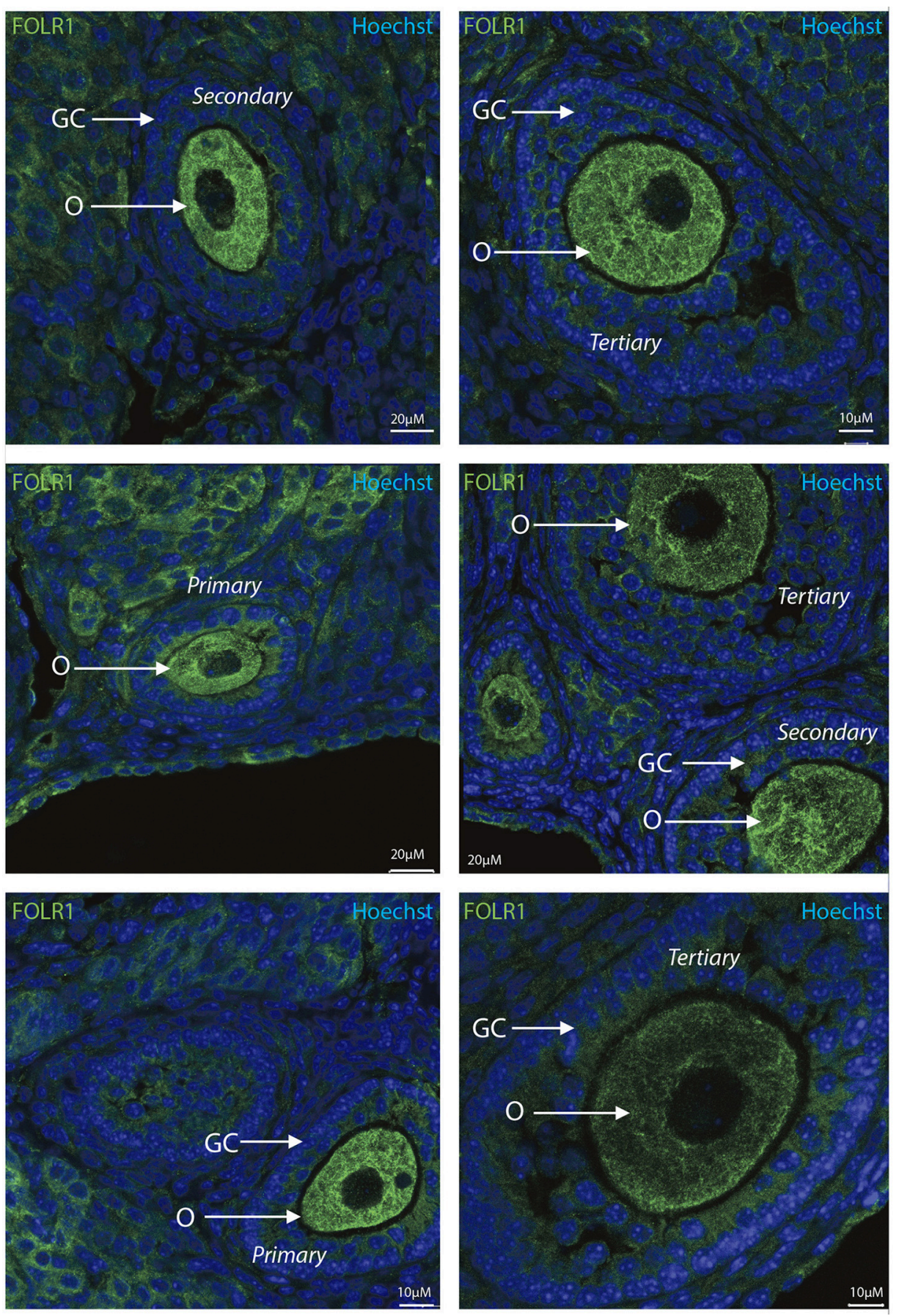

FIGURE 3 | Intraovarian distribution of FOLR in mouse ovary tissue. FOLR1 localized to oocytes in primary, secondary and tertiary follicles. Hoechts staining identifies the nucleus of cells in the slides and the surrounding granulosa cells. o, oocytes; GC, granulosa cells. Scale bars; 10 or $20 \mu \mathrm{m}$, as indicated.

Transcripts encoding the FOLR1 has not been investigated in ovarian follicles. However, a recent study enterrogated the transcriptomes in human oocytes from primordial and primary follicles, which did not detect expression of the FOLR1 gene (Ernst et al., 2017). Whether granulosa cells from primordial and primary follicles express the Folr 1 transcript remains to be investigated.
In agreements with another study, we found that Folrl transcription appeared to initiate at the 2-cell stage, which is further emphasized in a study that interrogated amantidine-sensitive transcrips, which included Folr1 (Zeng and Schultz, 2005). Interestingly, this appears to be conserved between different mice strains, as experiments were performed independently on three different strains [CF1 (Crl:CF1) females 

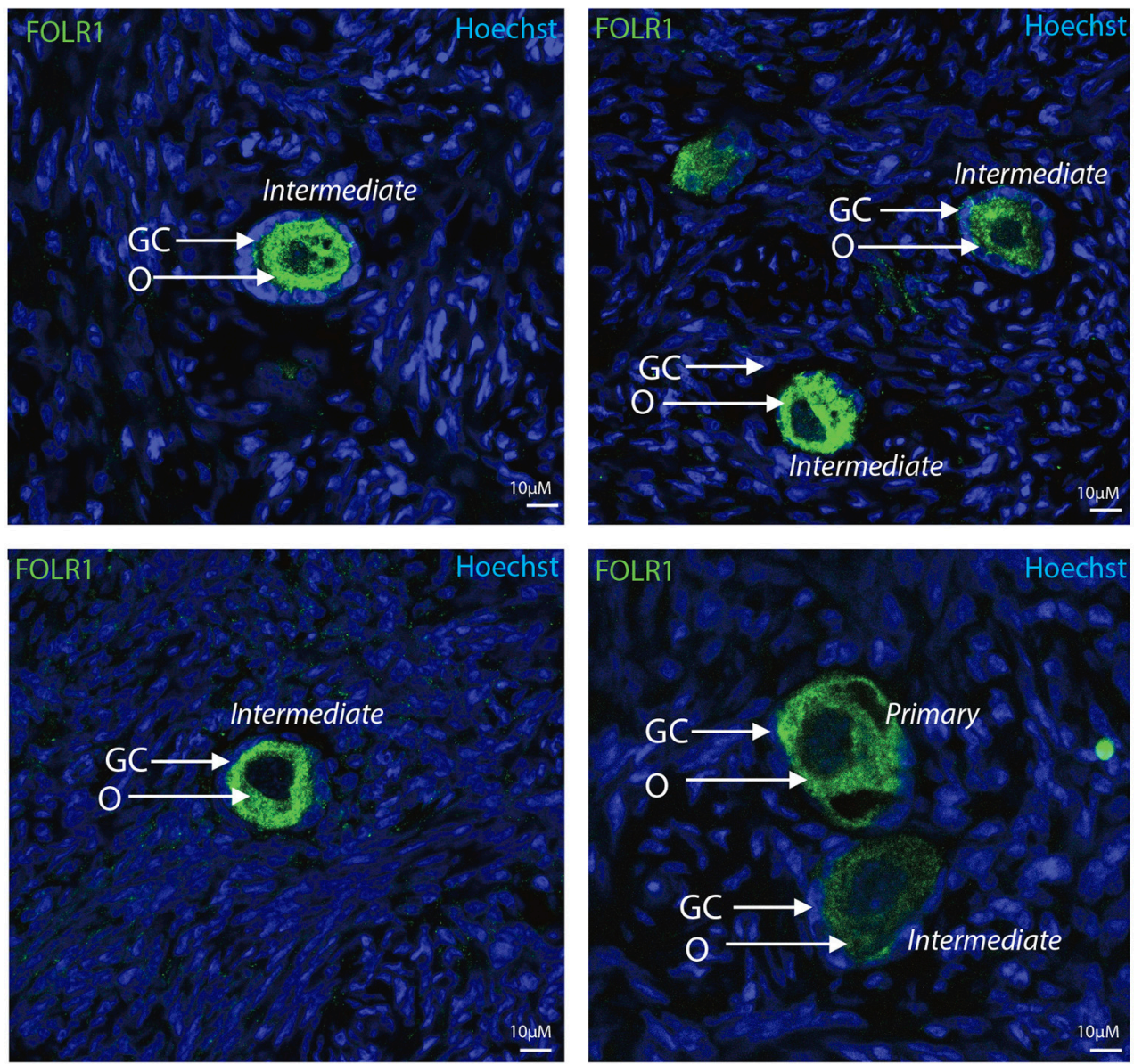

FIGURE 4 | Intraovarian distribution of FOLR in human ovary tissue. FOLR1 localized to oocytes in primary and intermediate follicles. Hoechts staining identifies the nucleus of cells in the slides and the surrounding granulosa cells. o, oocytes; GC, granulosa cells. Scale bars; $10 \mu \mathrm{m}$, as indicated.

(Charles River) and BDF1 (B6D2F1/Crl) males (Charles River) (Kooistra et al., 2013), superovulated female CF-1 mice (Harlan) mated to B6D2F1/J males (Jackson Laboratory) (Zeng and Schultz, 2005) and F1 [CBA (C57BL/6jxCBA) females and males (Janvier, this study).

Secreted FOLR1 proteins are either anchored to membranes via a glycosyl-phosphatidylinositol linkage or exist in a soluble form. The receptor-ligand complex is endocytosed into cytoplasmic vesicles and then recycled to the cell membrane. In our IHC, we accordingly observed FOLR1 at the cell membrane, but also noted it in the cytoplasm, resembling the intracellular transport of FOLR1. This might simply reflect the staus quo of the cell in the absence of active folate transport. Thus, in conclusion, it appears that oocyte folate accumulation must occur during follicle development, where folate is maternally supplied. The observation of the folate receptor in both oocytes and granulosa cells in the mouse follicles, but limited to oocytes in the follicles from human samples remains to be further investigated. Very low levels of the folate receptor and/or specific folate supplement might represent likely reasons that the folate receptor was not detected in human granulosa cells. FOLR1 appeared to be absent from the nucleus during follicle development, which suggest that during these stages in development, FOLR1 does not act as a transcription factor. This suggests that the function of FOLR1 during these stages is perhaps assigned predominantly to folate metabolism and signal transduction. Indeed, the role of TGF $\beta 1$ in ovarian physiology is well-know, and due to the fact that folate deficiency can alter this pathway, it might be that FOLR1 could influence this, as well, in ovarian follicles.

The FOLR1 distribution in 2-cell stage embryos was interogated using a eGFP fusion approach and the intracellular distribution of FOLR1-eGFP was comparable to that observed in the follicles. FOLR1-eGFP was concentrated at the cell membrane and further noted in cytoplasm, indicating that the FOLR1-eGFP follows the endogoues folate transport and makes this construct suitable for future studies on folate transport in embryonic cells.

Interestingly, while some of the embryos that were submitted to Folr1 RNAi were indeed able to complete development to the blastocyst stage, several arrest development during later preimplantation stages. This indicates that during preimplantation development, the levels of Folr1 transcript and FOLR1 protein are finely balanced to rely on maternally 

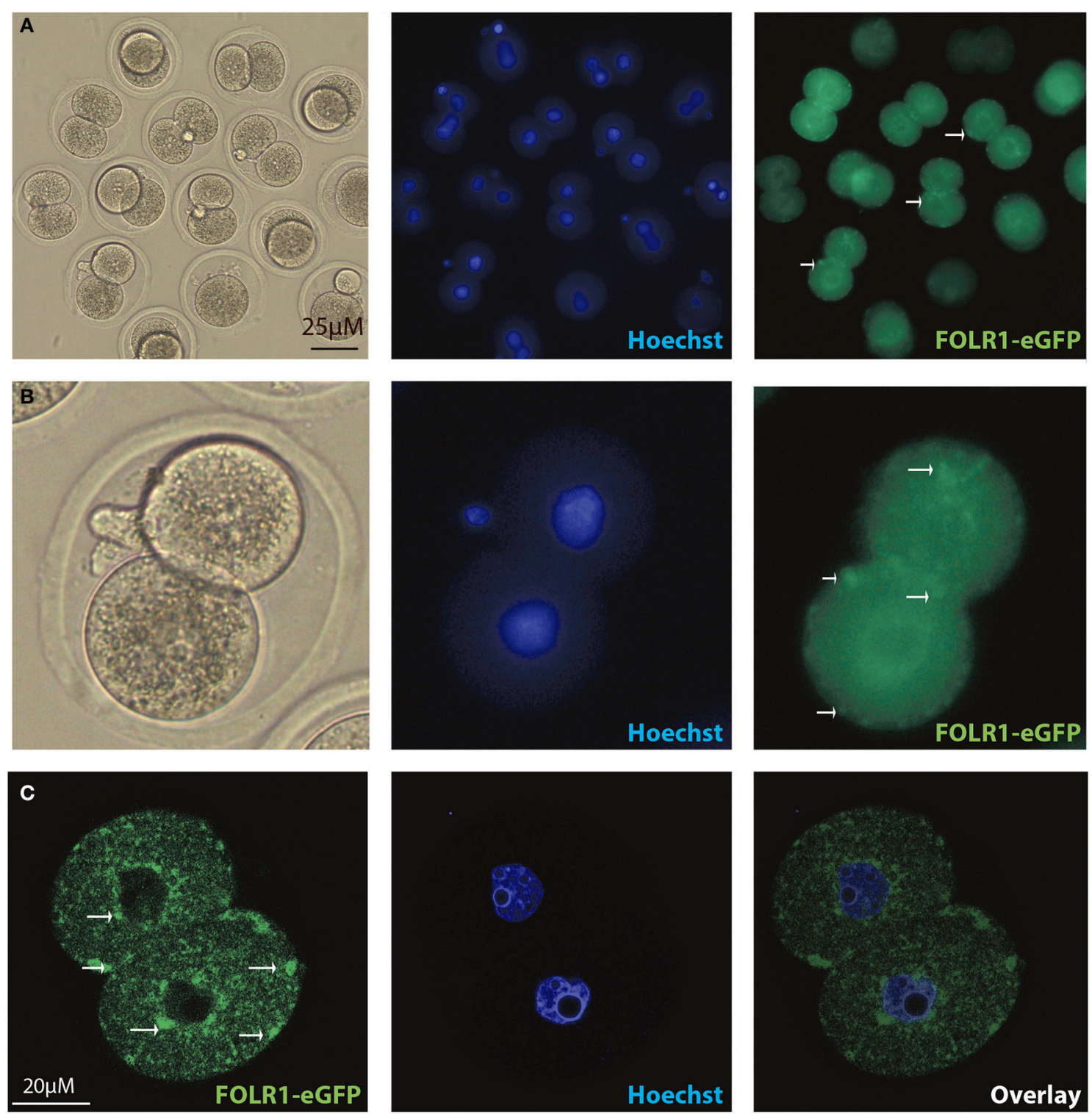

FIGURE 5 | Intracellular distribution of FOLR1-eGFP in mouse 2-cell embryos. Intracelluar immunofluorescent localization and distribution of FOLR1-eGFP in 2-cell mouse embryos using microscopic (A,B) confocal imaging (C). Scale bars 20 or $25 \mu \mathrm{M}$, as indicated.

contributed proteins and the generation of zygotically-derived Folr1. Thus, this suggests that indeed the maternal supply of FOLR1 protein remain during preimplantation and is partly sufficient to support the development until blastocyst stage. Developmental competences might therefore be much more dependent on the maternal internal pool of folate than previously anticipated and variations might account for folate-associated deficiencies.

In this context, it is curious to note that most in vitro-based experiments today are performed without folate supplement to the media, even though the long term consequences of folate deficiency in the medium is unknown. It opens a question whether or not we should in fact supplement in vitro culture media with folate. Further studies are needed to address whether variations in folate storage might influence developmental potential accordingly.

The long-term effect of Folr1 RNAi is not known, and it might be that depletion of Folr 1 could interfere with post-implantation. This is indeed in line with the fact that even low blood folate levels in pregnant women are correlated with higher risk of neural tube deficiency in their offspring (Smithells et al., 1976; Detrait et al., 2005), and periconceptional supplementation of folate reduces the occurrence of neural tube defects (Centers for Disease Control, 1991a,b; MRC Vitamin Study Research Group, 1991). Future studies are needed to elucidate the cellular and molecular mechanisms underlying folate and FOLR1 functions 

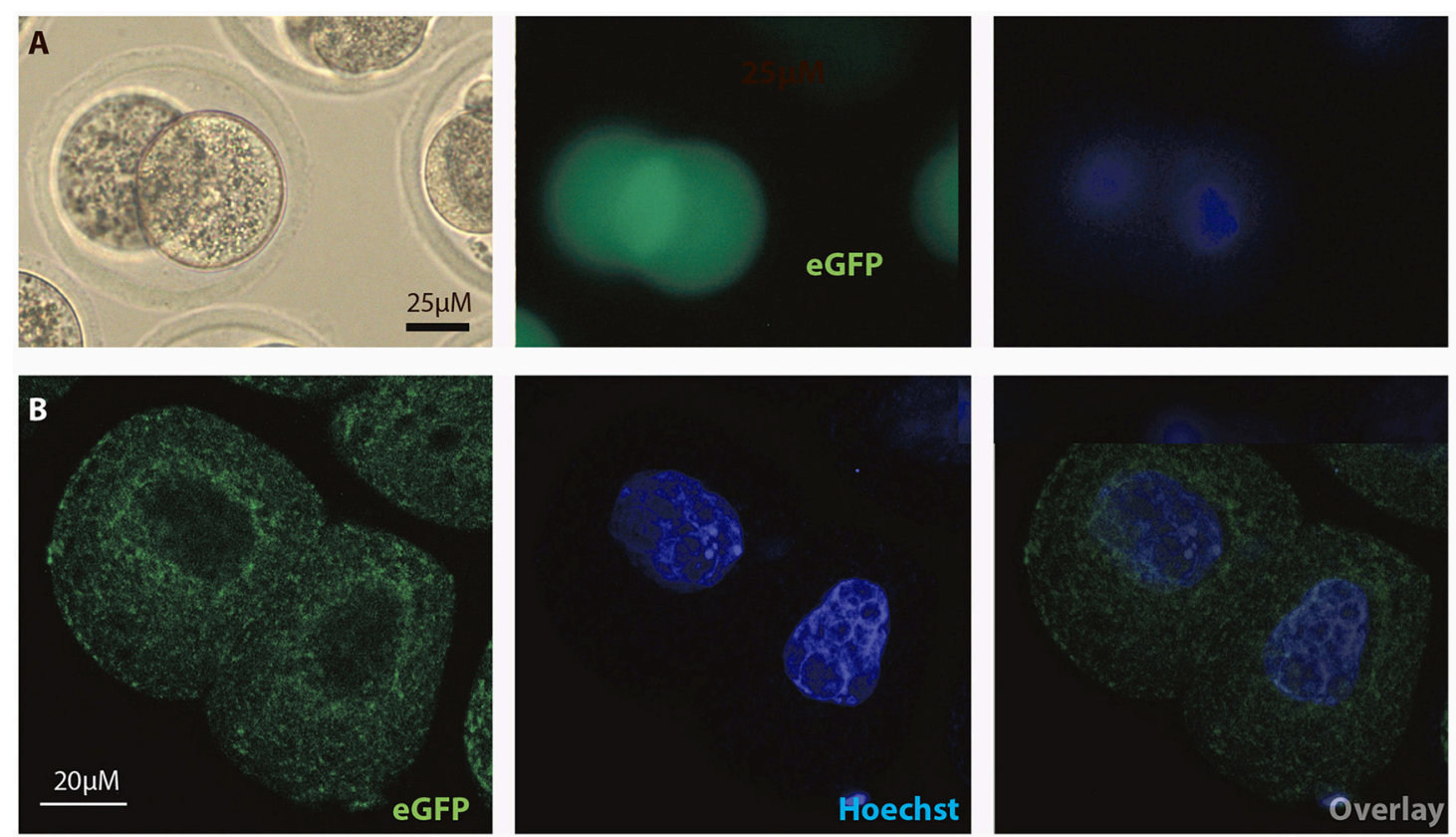

FIGURE 6 | Intracellular distribution of eGFP in mouse 2-cell embryos. Intracelluar immunofluorescent localization and distribution of eGFP in 2-cell mouse embryos using (A) microscopic and (B) confocal imaging. Scale bars 20 or $25 \mu \mathrm{M}$, as indicated.

and correlation between FOLR1 in preimplantation and early post-implantation development. This could include the CRISPCas9 technology and/or a conditional knock-out strategy to functionally knock-down the folate receptor before fertilization.

\section{MATERIALS AND METHODS \\ Embryo Isolation}

Embryo recovery and isolation F1 (C57BL/6xCBA) females were injected with 5 IU pregnant mare's serum gonadotrophin (PMSG; Folligon, Intervet) and with 5 IU human chorionic gonadotrophin (hCG; Chorulon; Intervet) 48 and $24 \mathrm{~h}$ later to induce ovulation, respectively, as described previously (Hogan et al., 1994), and mated with F1 (C57BL/6xCBA) males. Zygotes, 2-cell, 4-cell, and 8-cell embryos were collected at 26, 46, 56, and $64 \mathrm{~h}$ post hCG (Sigma), respectively. Blastocysts were collected at $72 \mathrm{~h}$ post hCG (Sigma). Zygotes for RNA injections were collected from female mice $25 \mathrm{~h}$ post-hCG. All procedures were approved by the Ethics Committee for the use of laboratory animals in Aarhus University (2015-15-0201-00800 to KLH). Zygotes were collected from the oviducts and treated with hyaluronidase (Sigma Aldrich) $(50 \mu \mathrm{l}$ of a $3 \mathrm{mg} / \mathrm{ml}$ solution in $250 \mu \mathrm{l}$ M2 medium) to remove surrounding cumulus cells and cultured in M2 media (EmbryoMax ${ }^{\circledR}$ M2 medium with phenol red, Specialty Media, Millipore MR-015P-5F) at $37^{\circ} \mathrm{C}$. Embryos were cultured overnight in drops of potassium simplex optimized medium (KSOM) (EmbryoMax KSOM Powdered Media Kit, Specialty Media, Millipore MR-020P-5F) supplemented with amino acids and $4 \mathrm{mg} / \mathrm{mL}$ BSA (Millipore) (no folate supplementation), under embryo-tested paraffin oil in an atmosphere of $5 \% \mathrm{CO}_{2}$ in air at $37^{\circ} \mathrm{C}$.

\section{RNA Isolation}

Total RNA extraction was performed using the RNeasy ${ }^{\circledR}$ Mini Kit (Qiagen). For each stage, 10-20 oocytes or embryos were collected and $350 \mu \mathrm{l}$ lysis buffer was used. Elution was performed with RNase-free water (Qiagen). For all RNA extractions, a DNase digestion step was performed, using the RNase-Free DNase Set (Qiagen). RNA was subsequently stored at $-80^{\circ} \mathrm{C}$.

\section{cDNA Synthesis}

Ovation ${ }^{\circledR}$ PicoSL WTA System V2 (Nugen) protocol was used to generate cDNA. For each cDNA synthesis reaction, 1.5-10 ng RNA was used.

\section{qPCR}

A qPCR analysis of the expression of the Folr1 gene was made from GV and MII oocytes, 2-cell, 4-cell, 8-cell and blastocyst embryos using the TaqMan ${ }^{\circledR}$ Gene Expression Assay (Applied Biosystems). Reactions were set up for the Folr1 gene and for the reference gene H2afz (Mamo et al., 2007). The reactions were run on a LightCycler ${ }^{\circledR} 96$ (Roche) using LightCycler ${ }^{\circledR} 480$ Probes Master (Roche) (Program: $50^{\circ} \mathrm{C}$ for $2 \mathrm{~s}, 95^{\circ} \mathrm{C}$ for $10 \mathrm{~min}, 45$ cycles of $95^{\circ} \mathrm{C}$ for $15 \mathrm{~s}$ followed by $60^{\circ} \mathrm{C}$ for $60 \mathrm{~s}$ and finally 1 cycle of $40^{\circ} \mathrm{C}$ for $30 \mathrm{~s}$ ). All reactions were done in triplets with $100 \mathrm{ng}$ of template cDNA in a total volume of $10 \mu \mathrm{l}$ containing $2 \mu \mathrm{l} \mathrm{H}_{2} \mathrm{O}$, $0.5 \mu l$ TaqMan Gene Expression Assays (Applied Biosystems) (see appendix 2), $5 \mu$ l Probes Master (Roche) and $2.5 \mu$ l template cDNA (40 $\mathrm{ng} / \mu \mathrm{l})$. Kidney was used as a positive control in the qPCR reaction. Experiments were repeated at least three times. Triplicate expression values of each gene was set relative to the reference gene via the $\Delta \Delta \mathrm{C}_{\mathrm{T}}$ methods (Schmittgen and Livak, 2008). As a negative control, cDNA from no template RT PCR 

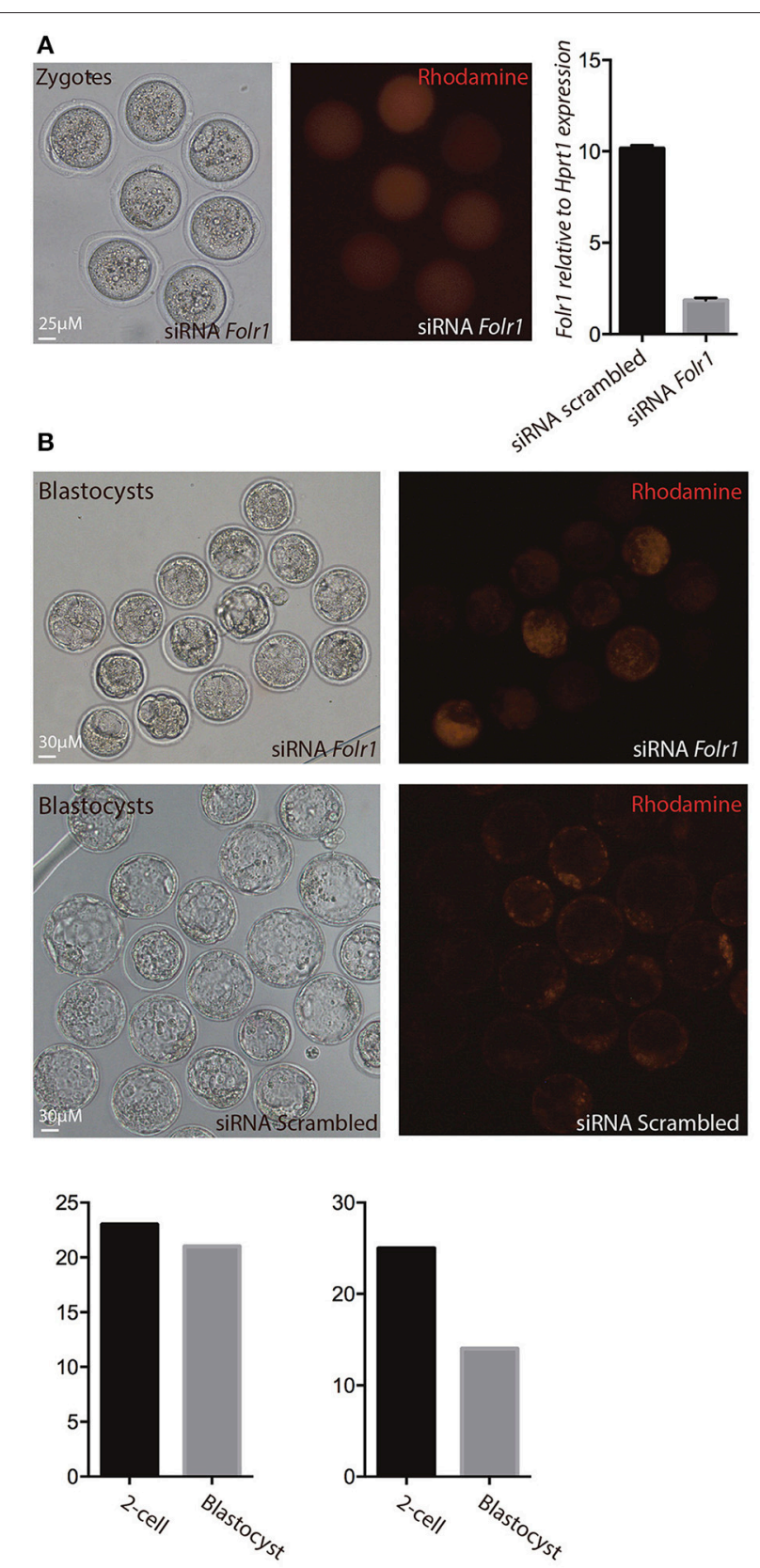

siRNA scrambled

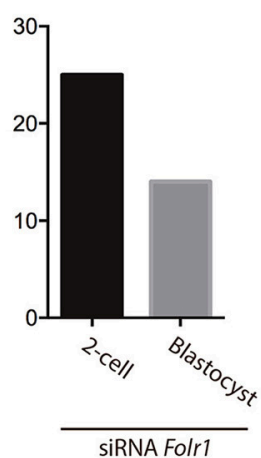

siRNA Folr 1

FIGURE 7 | siRNA-mediated knock-down of Folr1 in mouse zygotes. (A) siRNA probes targeting Folr1 (or scrambled control (not shown) was microinjected in combination with rhodamine-conjugated dextrane, in order to identify injected embryos. At the 2-cell stage, qPCR showed that Folr1 transcript is efficiently reduced after Folr1 RNAi. (B) After in vitro culture, siRNA-injected embryos (both RNAi scrambled and Folr 1 ) developed into blastocyst, however the capacity to form blastocysts was reduced in embryos that received siRNA targeting Folr1 (56\%) compared to the control RNAi group (92\%). Scale bars 25 or $30 \mu \mathrm{M}$, as indicated.

reactions was used. All $\mathrm{qPCR}$ data was analyzed using Prism 6, version 6.0 (GraphPad Software Inc., CA, U.S.A.). Data are represented as mean $\pm \mathrm{SD}$.

\section{Cloning of Folr1-eGfp}

Folr1 inserts were generated with SuperScript III One-Step RTPCR System with Platinum Taq High Fidelity (Invitrogen) using kidney RNA as template, and the following primers: Folr1-XmaF: $5^{\prime}$-NNNCCCGGGatggctcacctgatgactgtgc- $3^{\prime}$ and Folr1-XmaR: 5'-NNNCCCGGGGCTGATCACCCAGAGCAGCA-3'. Using $X m a I$ restriction sites, the PCR-amplified Folr 1 insert was cloned into the Xma1-digested and dephosporylated pBS_RN3P-eGFP vector (Lemaire et al., 1995), in frame with eGfp. Insert and orientation was verified by DNA sequencing.

\section{Immunohistochemistry} Tissue Collection, Paraffin Embedding, and

\section{Sectioning}

Mouse ovaries and kidneys were isolated from F1 females and kept overnight in 4\% PFA before embedding into paraffin. Human ovarian cortical tissue was procured from patients who underwent unilateral oophorectomy prior to gonadotoxic treatment for a malignant disease (unrelated to any ovarian malignancies). Patients were normo-ovulatory, with normal reproductive hormones, and had not received ovarian stimulation with exogenous gonadotropins. All methods were carried out in accordance with relevant guidelines and regulations, and The Central Denmark Region Committees on Biomedical Research Ethics and the Danish Data Protection Agency approved the study. Written informed consent was obtained from all participants before inclusion. Patients consented to the research conducted. In subjects undergoing oophorectomy, a small pieCe of the ovarian cortex is used for evaluating the ovarian reserve and for research purposes (Danish Scientific Ethical Committee Approval Number: KF 299017 and J/KF/01/170/99) (Schmidt et al., 2003).

Paraffin tissues were cut in sections of $10 \mu \mathrm{m}$. Hereafter, the sections were deparaffinized in xylene and rehydrated in graded ethanol series $(100,95,70 \%$, water) for $5 \mathrm{~min}$ in each vessel. The tissue sections were transferred to $0.01 \mathrm{M}$ citrate buffer (Citric acid and sodium citrate) for antigen retrieval and washed in PBS, and incubated with donkey serum ( $1 \mathrm{ml}$ donkey serum and $4 \mathrm{ml}$ PBS) for $30 \mathrm{~min}$ before adding primary FOLR1 antibody (diluted 1:100 (FOLR1 Rabbit anti-Human Polyclonal, LifeSpan BioSciences) overnight at $4^{\circ} \mathrm{C}$. The next day the tissues were washed in PBS and then incubated for $1 \mathrm{~h}$ at room temperature with the secondary donkey-anti-rabbit antibody [Alexa Fluor ${ }^{\circledR}$ 488 donkey anti-rabbit IgG (Invitrogen)] (dilution of 1:300). In the following washing steps, the tissues were counterstained with Hoechst (Sigma) to stain the nucleus, added to PBS in a dilution of 1:7,500. The tissues were mounted using Fluorescent Mounting Medium (DAKO S3023). Sections were analyzed and confocal images were taken using a LSM780 laser-scanning confocal microscope with 20, 40 and 63xC-Apochromat water/oil immersion objectives (Carl Zeiss, Jena, Germany).

\section{Western Blot}

Ovary, kidney and brain cortex were taken out from mice and lysed in a lysis buffer containing $7 \mathrm{ml}$ Tris-EDTA buffer $(10 \mathrm{mM}$ 
Tris- $\mathrm{HCl}, 1 \mathrm{mM}$ EDTA), 1 tablet of Complete Mini EDTAfree protease inhibitor (Roche) and $1 \%(70 \mu \mathrm{l})$ IGEPAL ${ }^{\circledR} \mathrm{CA}$ 630 (Sigma-Aldrich). $30 \mu \mathrm{g}$ of proteins from ovary, kidney and cortex were used for Western blotting analysis. Primary FOLR1 antibody (see appendix 8) was applied in a concentration of $0.5 \mu \mathrm{g} / \mathrm{ml}$ in the blocking buffer and the membrane was incubated overnight at $4^{\circ} \mathrm{C}$. The membrane was washed for $3 \times$ $10 \mathrm{~min}$ in PBS-Tween and secondary HRP-conjugated polyclonal swine-anti-rabbit antibody (DAKO S3023) was applied in a dilution of 1:1,000 in blocking buffer and incubated for $1 \mathrm{~h}$ at RT. The membrane was incubated in a chemiluminescent detection reagent. [ECLTM Western Blotting Analysis system (GE Healthcare)] and developed for $45 \mathrm{~s}$ using a ImageQuant LAS-4000 (GE Healthcare).

Endoglycosidase H (New England Biolabs, P0702S) treatment was performed according to the manufactorers instructions (New England Biolabs protocol).

\section{RNA Synthesis, Microinjections, and Confocal Imaging}

Generation of mRNA encoding FOLR1-GFP and GFP and microinjection into zygotes were performed as described (Albertsen et al., 2010). Microinjection of embryos with siRNA (ON_TARGETplus Mouse Folr1, Smartpool, L-061448-01-0005 and ON-TARGETplus Non-targeting Pool D-001810-10-05) with the final concentration of $20 \mu \mathrm{M}$, together with Rhodamineconjugated dextran as marker of injection) or mRNA (Folr1eGFP, or eGfp, 200-400 ng/ $\mu \mathrm{l}$ ) was carried out in M2 media (EmbryoMax ${ }^{\circledR}$ M2 medium with phenol red, Specialty Media, Millipore MR-015P-5F) covered in oil on a glass depression slide using a Femtojet micro-injection system (Eppendorf). Embryos were cultured in KSOM (EmbryoMax KSOM Powdered Media Kit, Specialty Media, Millipore MR-020P-5F) under paraffin oil at $37.5^{\circ} \mathrm{C}$ in air enriched with $5 \% \mathrm{CO}_{2}$. The microinjected

\section{REFERENCES}

Albertsen, M., Teperek, M., Elholm, G., Fuchtbauer, E. M., and Lykke-Hartmann, K. (2010). Localization and differential expression of the Kruppel-associated box zinc finger proteins 1 and 54 in early mouse development. DNA Cell Biol. 29, 589-601. doi: 10.1089/dna.2010.1040

Altmae, S., Stavreus-Evers, A., Ruiz, J. R., Laanpere, M., Syvanen, T., Yngve, A., et al. (2010). Variations in folate pathway genes are associated with unexplained female infertility. Fertil. Steril. 94, 130-137. doi: 10.1016/j.fertnstert.2009.02.025

Berrocal-Zaragoza, M. I., Fernandez-Ballart, J. D., Murphy, M. M., CavalleBusquets, P., Sequeira, J. M., and Quadros, E. V. (2009). Association between blocking folate receptor autoantibodies and subfertility. Fertil. Steril. 91, 1518-1521. doi: 10.1016/j.fertnstert.2008.08.104

Bianchi, E., Doe, B., Goulding, D., and Wright, G. J. (2014). Juno is the egg Izumo receptor and is essential for mammalian fertilization. Nature 508, 483-487. doi: 10.1038/nature13203

Blencowe, H., Cousens, S., Modell, B., and Lawn, J. (2010). Folic acid to reduce neonatal mortality from neural tube disorders. Int. J. Epidemiol. 39(Suppl. 1), i110-i121. doi: 10.1093/ije/dyq028

Boshnjaku, V., Shim, K. W., Tsurubuchi, T., Ichi, S., Szany, E. V., Xi, G., et al. (2012). Nuclear localization of folate receptor alpha: a new role as a transcription factor. Sci. Rep. 2:980. doi: 10.1038/srep 00980 zygotes were incubated overnight $\left(37^{\circ} \mathrm{C}, 5 \% \mathrm{CO}_{2}\right)$ in $\mathrm{KSOM}$ (EmbryoMax KSOM Powdered Media Kit, Specialty Media, Millipore MR-020P-5F). The next day, 2-cell embryos were incubated for $15 \mathrm{~min}$ in a $1: 7,500$ dilution of Hoechst (Sigma) in DPBS (Life Technologies), washed three times in PBS-T and fixed for $15 \mathrm{~min}$ in 2\% PFA, before mounting (Fluorescent Mounting Media, DAKO S3023). Embryos were analyzed using the fluorescent microscope (Leica DMI400B) and Leica LAS Software.

Confocal images were taken using a LSM800 laser-scanning confocal microscope with 20, 40, and 63xC-Apochromat water/oil immersion objectives NA 1.2 (Carl Zeiss, Jena, Germany). Confocal images were exported to ImageJ for image processing.

\section{AUTHOR CONTRIBUTIONS}

KL conceived the study. TS performed IHC/Western blot experiments. SF performed qPCR analyse. EE contributed with human tissue. $\mathrm{MN}$ and $\mathrm{KL}$ performed confocal analysis. $\mathrm{AH}$ conducted qPCR of siRNA experiments. KL performed siRNA microinjections and wrote the manuscript. All authors approved the final manuscript.

\section{ACKNOWLEDGMENTS}

The authors wish to thank past and current members of the Lykke-Hartmann laboratory (AU) for scientific discussions. We are particular grateful to Dr. Emil Hagen Ernst for his advice on human IHC. This work was supported by grants from Kong Christian Den Tiendes Fond, Th. Maigaards Eft. Fru Lily Benthine Lunds Fond, Toyota Fonden, Augustinus Fonden, and Fonden til Lægevidenskabens Fremme (to KL).
Brigle, K. E., Spinella, M. J., Westin, E. H., and Goldman, I. D. (1994). Increased expression and characterization of two distinct folate binding proteins in murine erythroleukemia cells. Biochem. Pharmacol. 47, 337-345. doi: 10.1016/0006-2952(94)90025-6

Burren, K. A., Scott, J. M., Copp, A. J., and Greene, N. D. (2010). The genetic background of the curly tail strain confers susceptibility to folate-deficiencyinduced exencephaly. Birth Defects Res. A Clin. Mol. Teratol. 88, 76-83. doi: 10.1002/bdra.20632

Cawley, S., Mullaney, L., McKeating, A., Farren, M., McCartney, D., and Turner, M. J. (2016). A review of European guidelines on periconceptional folic acid supplementation. Eur. J. Clin. Nutr. 70, 143-154. doi: 10.1038/ejcn.2015.131

Centers for Disease Control (1991a). Use of folic acid for prevention of spina bifida and other neural tube defects-1983-1991. JAMA 266, 1190-1191. doi: 10.1001/jama.1991.03470090024009

Centers for Disease Control (1991b). Effectiveness in disease and injury prevention use of folic acid for prevention of spina bifida and other neural tube defects 1983-1991. MMWR Morb. Mortal. Wkly. Rep. 40, 513-516.

Chen, C., Ke, J., Zhou, X. E., Yi, W., Brunzelle, J. S., Li, J., et al. (2013). Structural basis for molecular recognition of folic acid by folate receptors. Nature 500, 486-489. doi: 10.1038/nature12327

Cragan, J. D., Roberts, H. E., Edmonds, L. D., Khoury, M. J., Kirby, R. S., Shaw, G. M., et al. (1995). Surveillance for anencephaly and spina bifida and the impact of prenatal diagnosis-United States, 1985-1994. MMWR CDC Surveill. Summ. $44,1-13$ 
Crott, J. W., Liu, Z., Keyes, M. K., Choi, S. W., Jang, H., Moyer, M. P., et al. (2008). Moderate folate depletion modulates the expression of selected genes involved in cell cycle, intracellular signaling and folate uptake in human colonic epithelial cell lines. J. Nutr. Biochem. 19, 328-335. doi: 10.1016/j.jnutbio.2007.05.003

Czeizel, A. E., and Dudas, I. (1992). Prevention of the first occurrence of neuraltube defects by periconceptional vitamin supplementation. N. Engl. J. Med. 327, 1832-1835. doi: 10.1056/NEJM199212243272602

da Costa, M., Sequeira, J. M., Rothenberg, S. P., and Weedon, J. (2003). Antibodies to folate receptors impair embryogenesis and fetal development in the rat. Birth Defects Res. A Clin. Mol. Teratol. 67, 837-847. doi: 10.1002/bdra.10088

De-Regil, L. M., Pena-Rosas, J. P., Fernandez-Gaxiola, A. C., and Rayco-Solon, P. (2015). Effects and safety of periconceptional oral folate supplementation for preventing birth defects. Cochrane Database Syst. Rev. 6:CD007950. doi: 10.1002/14651858.CD007950.pub3

Desai, A., Sequeira, J. M., and Quadros, E. V. (2016). The metabolic basis for developmental disorders due to defective folate transport. Biochimie 126, 31-42. doi: 10.1016/j.biochi.2016.02.012

Detrait, E. R., George, T. M., Etchevers, H. C., Gilbert, J. R., Vekemans, M., and Speer, M. C. (2005). Human neural tube defects: developmental biology, epidemiology, and genetics. Neurotoxicol. Teratol. 27, 515-524. doi: 10.1016/j.ntt.2004.12.007

Ernst, E. H., Grøndahl, M. L., Grund, S., Hardy, K., Heuck, A., Sunde, L., et al. (2017). Dormancy and activation of human oocytes from primordial and primary follicles: molecular clues to oocyte regulation. Hum. Reprod. 32, 1684-1700. doi: 10.1093/humrep/dex238

Fowler, B. (2001). The folate cycle and disease in humans. Kidney Int. Suppl. 78, S221-S229. doi: 10.1046/j.1523-1755.2001.07851.x

Frye, R. E., Slattery, J., Delhey, L., Furgerson, B., Strickland, T., Tippett, M., et al. (2016). Folinic acid improves verbal communication in children with autism and language impairment: a randomized double-blind placebo-controlled trial. Mol. Psychiatry. doi: 10.1038/mp.2016.168. [Epub ahead of print].

Gao, Y., Sheng, C., Xie, R. H., Sun, W., Asztalos, E., Moddemann, D., et al. (2016). New perspective on impact of folic acid supplementation during pregnancy on Neurodevelopment/Autism in the offspring children - a systematic review. PLoS ONE 11:e0165626. doi: 10.1371/journal.pone.0165626

George, L., Mills, J. L., Johansson, A. L., Nordmark, A., Olander, B., Granath, F., et al. (2002). Plasma folate levels and risk of spontaneous abortion. JAMA 288, 1867-1873. doi: 10.1001/jama.288.15.1867

Hibbard, B. M. (1964). The role of folic acid in pregnancy; with particular reference to anaemia, abruption and abortion. J. Obstet. Gynaecol. Br. Commonw. 71, 529-542. doi: 10.1111/j.1471-0528.1964.tb04317.x

Hogan, B., Beddington, R., Costantini, F., and Lacy, E. (1994). Manipulating the Mouse Embryo: A Laboratory Manual, 2 Edn. Cold Spring Habor Laboratory Press.

Jeong, Y. J., Choi, H. W., Shin, H. S., Cui, X. S., Kim, N. H., Gerton, G. L., et al. (2005). Optimization of real time RT-PCR methods for the analysis of gene expression in mouse eggs and preimplantation embryos. Mol. Reprod. Dev. 71, 284-289. doi: 10.1002/mrd.20269

Kooistra, M., Trasler, J. M., and Baltz, J. M. (2013). Folate transport in mouse cumulus-oocyte complexes and preimplantation embryos. Biol. Reprod. 89:63. doi: 10.1095/biolreprod.113.111146

Lemaire, P., Garrett, N., and Gurdon, J. B. (1995). Expression cloning of Siamois, a Xenopus homeobox gene expressed in dorsal-vegetal cells of blastulae and able to induce a complete secondary axis. Cell 81, 85-94. doi: 10.1016/0092-8674(95)90373-9

Mamo, S., Gal, A. B., Bodo, S., and Dinnyes, A. (2007). Quantitative evaluation and selection of reference genes in mouse oocytes and embryos cultured in vivo and in vitro. BMC Dev. Biol. 7:14. doi: 10.1186/1471-213X-7-14

MRC Vitamin Study Research Group (1991). Prevention of neural tube defects results of the Medical Research Council Vitamin Study. MRC Vitamin Study Research Group. Lancet 338, 131-137.

Padmanabhan, N., Jia, D., Geary-Joo, C., Wu, X., Ferguson-Smith, A. C., Fung, E., et al. (2013). Mutation in folate metabolism causes epigenetic instability and transgenerational effects on development. Cell 155, 81-93. doi: 10.1016/j.cell.2013.09.002

Piedrahita, J. A., Oetama, B., Bennett, G. D., Van Waes, J., Kamen, B. A., Richardson, J., et al. (1999). Mice lacking the folic acid-binding protein Folbp1 are defective in early embryonic development. Nat. Genet. 23, 228-232. doi: $10.1038 / 13861$
Pitkin, R. M. (2007). Folate and neural tube defects. Am. J. Clin. Nutr. 85, 285S-288S

Ramaekers, V. T., Blau, N., Sequeira, J. M., Nassogne, M. C., and Quadros, E. V. (2007). Folate receptor autoimmunity and cerebral folate deficiency in lowfunctioning autism with neurological deficits. Neuropediatrics 38, 276-281. doi: 10.1055/s-2008-1065354

Ramaekers, V. T., Rothenberg, S. P., Sequeira, J. M., Opladen, T., Blau, N., Quadros, E. V., et al. (2005). Autoantibodies to folate receptors in the cerebral folate deficiency syndrome. N. Engl. J. Med. 352, 1985-1991. doi: 10.1056/NEJMoa043160

Ramaekers, V. T., Sequeira, J. M., and Quadros, E. V. (2016). The basis for folinic acid treatment in neuro-psychiatric disorders. Biochimie 126, 79-90. doi: 10.1016/j.biochi.2016.04.005

Rosenquist, T. H., Chaudoin, T., Finnell, R. H., and Bennett, G. D. (2010). Highaffinity folate receptor in cardiac neural crest migration: a gene knockdown model using siRNA. Dev. Dyn. 239, 1136-1144. doi: 10.1002/dvdy.22270

Rothenberg, S. P., Da Costa, M. P., Sequeira, J. M., Cracco, J., Roberts, J. L., Weedon, J., et al. (2004). Autoantibodies against folate receptors in women with a pregnancy complicated by a neural-tube defect. N. Engl. J. Med. 350, 134-142. doi: 10.1056/NEJMoa031145

Schmidt, K. L., Byskov, A. G., Nyboe Andersen, A., Muller, J., and Yding Andersen, C. (2003). Density and distribution of primordial follicles in single pieces of cortex from 21 patients and in individual pieces of cortex from three entire human ovaries. Hum. Reprod. 18, 1158-1164. doi: 10.1093/humrep/deg246

Schmittgen, T. D., and Livak, K. J. (2008). Analyzing real-time PCR data by the comparative $\mathrm{C}(\mathrm{T})$ method. Nat. Protoc. 3, 1101-1108. doi: $10.1038 /$ nprot.2008.73

Sequeira, J. M., Ramaekers, V. T., and Quadros, E. V. (2013). The diagnostic utility of folate receptor autoantibodies in blood. Clin. Chem. Lab. Med. 51, 545-554. doi: 10.1515/cclm-2012-0577

Shen, F., Wu, M., Ross, J. F., Miller, D., and Ratnam, M. (1995). Folate receptor type gamma is primarily a secretory protein due to lack of an efficient signal for glycosylphosphatidylinositol modification: protein characterization and cell type specificity. Biochemistry 34, 5660-5665. doi: 10.1021/bi00016a042

Smithells, R. W., Sheppard, S., and Schorah, C. J. (1976). Vitamin deficiencies and neural tube defects. Arch. Dis. Child. 51, 944-950. doi: 10.1136/adc.51.12.944

Spiegelstein, O., Eudy, J. D., and Finnell, R. H. (2000). Identification of two putative novel folate receptor genes in humans and mouse. Gene 258, 117-125. doi: 10.1016/S0378-1119(00)00418-2

Stover, P. J. (2009). One-carbon metabolism-genome interactions in folateassociated pathologies. J. Nutr. 139, 2402-2405. doi: 10.3945/jn.109.113670

Sudiwala, S., De Castro, S. C., Leung, K. Y., Brosnan, J. T., Brosnan, M. E., Mills, K., et al. (2016). Formate supplementation enhances folate-dependent nucleotide biosynthesis and prevents spina bifida in a mouse model of folic acid-resistant neural tube defects. Biochimie 126, 63-70. doi: 10.1016/j.biochi.2016.02.010

Taparia, S., Gelineau-Van Waes, J., Rosenquist, T. H., and Finnell, R. H. (2007). Importance of folate-homocysteine homeostasis during early embryonic development. Clin. Chem. Lab. Med. 45, 1717-1727. doi: 10.1515/CCLM.2007.345

Van Straaten, H. W., and Copp, A. J. (2001). Curly tail: a 50-year history of the mouse spina bifida model. Anat. Embryol. 203, 225-237. doi: $10.1007 / \mathrm{s} 004290100169$

Warner, D. R., Webb, C. L., Greene, R. M., and Pisano, M. M. (2011). Altered signal transduction in Folr1-/- mouse embryo fibroblasts. Cell Biol. Int. 35, 1253-1259. doi: 10.1042/CBI20110025

Zeng, F., and Schultz, R. M. (2005). RNA transcript profiling during zygotic gene activation in the preimplantation mouse embryo. Dev. Biol. 283, 40-57. doi: 10.1016/j.ydbio.2005.03.038

Conflict of Interest Statement: The authors declare that the research was conducted in the absence of any commercial or financial relationships that could be construed as a potential conflict of interest.

Copyright (c) 2017 Strandgaard, Foder, Heuck, Ernst, Nielsen and Lykke-Hartmann. This is an open-access article distributed under the terms of the Creative Commons Attribution License (CC BY). The use, distribution or reproduction in other forums is permitted, provided the original author(s) or licensor are credited and that the original publication in this journal is cited, in accordance with accepted academic practice. No use, distribution or reproduction is permitted which does not comply with these terms. 